\title{
Foaming of Acid-Hydrolyzed Insoluble Microalgae Proteins from Chlorella protothecoides
}

\author{
Laixin Dai $^{1}$ - Rashmi Shivananda ${ }^{1}$ - Jörg Hinrichs ${ }^{2}$ • Jochen Weiss ${ }^{1}$ \\ Received: 20 January 2020 / Accepted: 18 March 2020 / Published online: 14 April 2020 \\ (C) The Author(s) 2020
}

\begin{abstract}
Microalgae are considered to be a promising alternative protein source after extraction and fractionation. Studies have shown that the insoluble protein fraction possesses interfacial activity and is able to stabilize oil-in-water emulsions after acid hydrolysis. The current work studied the surface pressure and foaming properties of the insoluble microalgae protein fraction obtained from Chlorella protothecoides and two of their hydrolysates. Results showed that the surface pressure of the three used protein fractions increased with increasing protein concentration. Moreover, surface pressure of the insoluble microalgae protein increased after hydrolysis at $65^{\circ} \mathrm{C}$ (Hydrolysates 65 ) or $85^{\circ} \mathrm{C}$ (Hydrolysates 85) suggesting an increased foaming capacity of the insoluble microalgae protein fraction after hydrolysis. Hydrolysates 85 had the highest foam capacity, and foams remained stable with a half-life time of over $5 \mathrm{~h}$. Overall, hydrolysis of the insoluble microalgae protein fraction with $0.5 \mathrm{M} \mathrm{HCl}$ at $85^{\circ} \mathrm{C}$ for $4 \mathrm{~h}$ resulted in generation of protein fragments that appear to be very suitable to stabilize air-water interfaces in foam-based foods.
\end{abstract}

Keywords Insoluble protein $\cdot$ Microalgae $\cdot$ Hydrolysis $\cdot$ Surface pressure $\cdot$ Foaming

\section{Introduction}

Microalgae have been reported in recent decades as a promising protein source to substitute animal-derived or agriculturallyderived plant proteins [1-3]. This may be attributed to their abundant protein content, well-balanced amino acid composition, high adaptability to various growth conditions, and low resource use [4-7]. The techno-functional properties of various microalgae protein fractions have been studied in recent years, in particular, those of the soluble microalgae protein fraction [8-11]. However, the techno-functional properties of the insoluble microalgae protein fraction, which makes up almost $50 \%$

Electronic supplementary material The online version of this article (https://doi.org/10.1007/s11483-020-09630-2) contains supplementary material, which is available to authorized users.

Jochen Weiss

j.weiss@uni-hohenheim.de

$1 \quad$ Department of Food Physics and Meat Science, Institute of Food Science and Biotechnology, University of Hohenheim, Garbenstrasse 21/25, 70599 Stuttgart, Germany

2 Department of Soft Matter Science and Dairy Technology, Institute of Food Science and Biotechnology, University of Hohenheim, Garbenstrasse 21, 70599 Stuttgart, Germany of the total microalgae protein, has been limited by its low solubility and the presence of large protein aggregate particles that tend to sediment [2]. Acid hydrolysis at elevated temperatures has shown to be a possible way to improve technofunctional properties of insoluble proteins by inducing greater conformational flexibility improving their ability to adsorb to interfaces and thereby stabilize for example oil-in-water emulsions [2].

In this study, we examined the foamability and stability of foams made with an untreated insoluble microalgae protein fraction and their hydrolysates obtained from the biomass of Chlorella protothecoides. Foams have been used for some time in the food industry providing specific organoleptic profiles such as mouthfeel and appearances. These properties are of importance in for example dairy products, egg products, beer, or cakes $[12,13]$. Foams are two-phase systems with air being dispersed in a liquid phase in the form of small bubbles, which is similar to emulsions where a second liquid phase is dispersed in a primary one in the form of small droplets. Both systems contain large amounts of interfaces or surfaces, and therefore generally require surfactants to be formed and stabilized $[14,15]$. The foamability of surface-active agents such as e.g. certain proteins depends on their surface activity, that is how much and how fast they can adsorb and spread at surfaces or interfaces. In addition, while both emulsion and foams profit from interfacial films being cohesive 
and viscoelastic, this is of particular importance for the latter systems [16-18].

In a previous study, it was shown that the interfacial activity of an insoluble microalgae protein fraction from Chlorella protothecoides was enhanced after hydrolysis with $0.5 \mathrm{M}$ $\mathrm{HCl}$ at $65{ }^{\circ} \mathrm{C}$ (Hydrolysates 65 ) or $85{ }^{\circ} \mathrm{C}$ (Hydrolysates 85) for $4 \mathrm{~h}$ due to a higher solubility, smaller molecular weights, and a more flexible protein structure [19]. Therefore, we hypothesized that this may also lead to an improved ability to stabilize foams. Consequently, we compared the foaming behavior of Hydrolysates 65 and Hydrolysates 85 with that of the untreated insoluble microalgae protein fraction. To that purpose, the surface pressure and the foaming behavior of the untreated insoluble microalgae protein fraction, the Hydrolysates 65, and the Hydrolysates 85 were examined.

\section{Materials and Methods}

\section{Materials}

Biomass of Chlorella protothecoides was purchased from Roquette Frères (Lestrem, France). The insoluble microalgae protein fraction was extracted by a solvent (ethanol: acetone = 1: 1) after high-pressure treatment using a micro-fluidizer and fractionation using centrifugal separation according to a published method by Grossmann et al. [20]. The extracted insoluble microalgae protein fraction was hydrolyzed at 65 or $85{ }^{\circ} \mathrm{C}$ in $0.5 \mathrm{M} \mathrm{HCl}$ for $4 \mathrm{~h}$, dialyzed and freeze-dried with modification according to Dai et al. [2, 21]. The untreated insoluble microalgae protein fraction contains $63.3 \pm 2.9 \%$ protein with a solubility of $11.3 \pm 0.1 \%$; the protein content of Hydrolysates 65 and Hydrolysates 85 is $57.9 \pm 0.1 \%$ and $55.3 \pm 0.2 \%$ having solubility of $47.2 \pm 0.7 \%$ and $63.3 \pm$ $1.5 \%$, respectively [22].

\section{Surface Tension}

Surface tension was determined using a drop shape analyzer (DSA 10, Krüss GmbH, Hamburg, Germany) [23]. A drop of suspension of untreated insoluble microalgae protein, Hydrolysates 65 or Hydrolysates 85 with protein concentrations ranging from $0.01 \%$ to $0.5 \%(\mathrm{w} / \mathrm{w})$ was suspended at the tip of the needle with an outer diameter of $1.26 \mathrm{~mm}$. The surface tension was calculated according to the YoungLaplace equation based on the shape area of the formed drop [24]. The interface was equilibrated for $30 \mathrm{~min}$ at room temperature. The densities of the protein dispersions required for the surface tension measurement were determined using a hand-held digital density meter (DMA 35 N, Anton Paar, Graz, Austria). The surface pressure was then calculated according to eq. (1):
$\Pi=\gamma_{W}-\gamma_{P}$

where $\Pi$ is the surface pressure $(\mathrm{mN} / \mathrm{m}), \gamma_{W}$ is the surface tension $(\mathrm{mN} / \mathrm{m})$ of the buffer (with $0.03 \%$ sodium azide) and $\gamma_{P}$ is the surface tension $(\mathrm{mN} / \mathrm{m})$ of the respective protein dispersion.

For the surface pressure in a function of protein concentration, the equilibrium surface pressure from a non-linear fit analysis was used. The fit function was $y=y 0+A^{*} \exp .(R 0 * x)$. The detailed fit analysis results were in the electronic supplementary material (ESM).

\section{Foam Formation}

Foams were formed by a sparging method in a custom-made foam analyzer described by Ewert. et al. [25]. An amount of $40 \mathrm{~mL}$ of protein dispersion was carefully added into the jacketed column (outer diameter: $6.5 \mathrm{~cm}$; inner diameter: $4 \mathrm{~cm}$, length: $25 \mathrm{~cm}$ ) with the help of a glass stirring rod to avoid foaming. The pressure air was sparged into the glass column through a ceramic frit (10-16 $\mu \mathrm{m}$, Glasgerätebau OCHS Laborfachhandel e.K. Bovenden, Germany) at a flow rate of $200 \mathrm{~mL} / \mathrm{min}$ controlled by a mass flow meter (Fischer \& Porter GmbH, Ellershausen, Germany) for $1 \mathrm{~min}$ at room temperature. The foaming properties (see below) of the protein dispersion at concentrations of $0.1 \%, 0.5 \%, 1 \%$, and $5 \%$ at their native $\mathrm{pH}(6.7 \pm 0.3)$ were then determined.

\section{Morphology of the Foams and Bubble Diameter}

A digital camera (Canon Power shot G10, Canon Inc., Tokyo, Japan) was used to capture the structure of foams after sparging, and every $10 \mathrm{~min}$ thereafter during a $2 \mathrm{~h}$ storage test. The foams above the liquid-foam border were recorded together with a scale to determine the diameter of the bubbles. Bubble diameters were calculated with Image J 1.50v (National Institute of Health, Bethesda, Maryland, USA). To that purpose, the foam images were exported to Image $J$ and transferred to an 8-bit version. The scale was calibrated by converting pixels to $\mathrm{cm}$. The contrast and brightness were adjusted to highlight the bubbles. Either 30 bubbles or all bubbles, if less than 30 bubbles were on the image, were selected in each image (except foams formed with $0.1 \%$ untreated insoluble microalgae protein fraction), and filled with black. The binary and watershed functions were applied prior to analyzing the median bubble area $\left(A, \mathrm{~cm}^{2}\right)$. The equivalent bubble diameter $(d, \mathrm{~cm})$ was finally calculated according to eq. (2):

$d=2 * \sqrt{\frac{A}{\pi}}$ 


\section{Foam Volume}

The foam volume was recorded by measuring foam height in the glass column immediately after sparging. The foam height $\left(\mathrm{h}_{\mathrm{f}}, \mathrm{cm}\right)$ was read from a scale pasted on the outside of the glass column. The foam volume $\left(\mathrm{V}_{\mathrm{f}}, \mathrm{mL}\right)$ was calculated according to eq. (3):

$V_{f}=\pi r^{2} * h_{f}$

in which $r$ represents the inside radius (equals $2 \mathrm{~cm}$ ) of the glass column.

\section{Liquid Fraction in Foam}

The liquid fraction in foam was calculated by the ratio of volume of liquid in foam and volume of foam. The volume of liquid in foam was determined by the volume decrease of protein dispersions in the glass column before and after foaming.

\section{Foam Half-Life Time}

The foam half-life time was defined as the time when half of the foam volume remained in the column after the foam formation. If the foam half-life time was lower than an-hour, the foam stability would be presented as + . If the foam half-life time was $2-3 \mathrm{~h}, 4-5 \mathrm{~h}$ or above $5 \mathrm{~h}$, the foam stability would be presented as,+++++ , or ++++ respectively.

\section{Statistical Analysis}

All measurements were conducted at least three times for each of the two freshly prepared samples. Means and standard deviations were calculated with Excel 2013 (Microsoft Corporation, Redmond, Washington State, USA). Figures were created with OriginPro 2017 (OriginLab, Northampton, Massachusetts, USA). Image analysis was carried out with Image J 1.50v (National Institutes of Health, Bethesda, Maryland, USA). A one-way analysis of variance (ANOVA) using the Tukey test was performed (SPSS Statistics V21, IBM Corp., Armonk, USA). The $\alpha$-level of 0.05 is considered as significantly different.

\section{Results and Discussion}

\section{Surface Pressure}

The ability of proteins to rapidly diffuse and adsorb to the interface to form interconnected interfacial layers is critical for foam formation [26]. Therefore, the dynamic surface pressure and the surface pressure of the differently treated protein fractions at different concentrations $(0.01 \%-0.5 \%)$ were determined at the air-water interface. Herein, the time-dependent development of the surface pressure is indicative of a decrease in surface tension and yields information about the adsorption behavior of proteins. The surface pressure was plotted as a function of the square root of the adsorption time to better illustrate differences in the adsorption rate between samples $[27,28]$. The surface pressure and the adsorption rate of the untreated insoluble microalgae protein increased with increasing concentration (Fig. 1A). The surface pressure stayed around $0 \mathrm{mN} / \mathrm{m}$ at $0.01 \%$ during the tested adsorption time, indicating that the material had little or no effect on surfacerelated free energy minimizations. At higher concentrations, lag periods could be observed: Specifically, the untreated insoluble microalgae protein showed decreasing lag times at $0.075 \%, 0.15 \%$ or $0.3 \%$ revealing a highly time-dependent increase in surface pressure, which may be attributed to a structural rearrangement and unfolding of protein aggregates prior to adsorption at the air-water interface [29, 30]. For Hydrolysates 65 or Hydrolysates 85, shorter and overall less pronounced lag phases were observed which were limited to a concentration of $0.01 \%$ (Fig. 1B, C). Furthermore, the surface pressure of the two hydrolysates increased more rapidly in the initial stage of the adsorption compared to the untreated insoluble microalgae protein indicating that the hydrolysates adsorbed at and covered the interface more effectively (Fig. 1). This is indicative of an improved interfacial activity of Hydrolysates 65 and Hydrolysates 85 at the air-water interface, and thus a potential higher foaming ability. The hydrolyzed protein fractions were composed of protein aggregates and particles having an overall lower molecular weight and greater conformational flexibility which may have promoted a more rapid molecular diffusion and adsorption at the interface [31-33].

The critical protein concentration has been defined as the concentration at which the surface pressure becomes independent of the surfactant concentration, and can be obtained from adsorption equilibrium plots i.e. the concentration where a plateau region begins $[28,34]$. To that purpose, we plotted the equilibrium surface pressure as a function of the protein concentration (Fig. 1D). Firstly, the equilibrium surface pressure of the untreated insoluble microalgae protein increased with protein concentrations, but surface pressures of Hydrolysates 65 and Hydrolysates 85 tended to reach a plateau earlier at a concentration at $0.3 \%$ and $0.1 \%$, to assume finite surface pressures of $29.9 \pm 0.1 \mathrm{mN} / \mathrm{m}$ and $31.9 \pm 0.2$ $\mathrm{mN} / \mathrm{m}$, respectively (Fig. 1D). This shows that hydrolysates are generally able to fully cover the air-water interface at lower concentrations of protein, which is likely due to an increased amount of smaller molecules able to unfold, spread and rearrange faster at the interface. In contrast, within the concentration range tested, no such critical concentration could be found for the untreated microalgae protein fraction, indicating 
Fig. 1 Surface pressure of untreated insoluble microalgae protein fraction (untreated IMPF), Hydrolysates 65 and Hydrolysates 85 as a function of the square root of time (A, B, C). Equilibrium surface pressure as a function of protein concentration $(0.01 \%-0.5 \%, \mathrm{D})$

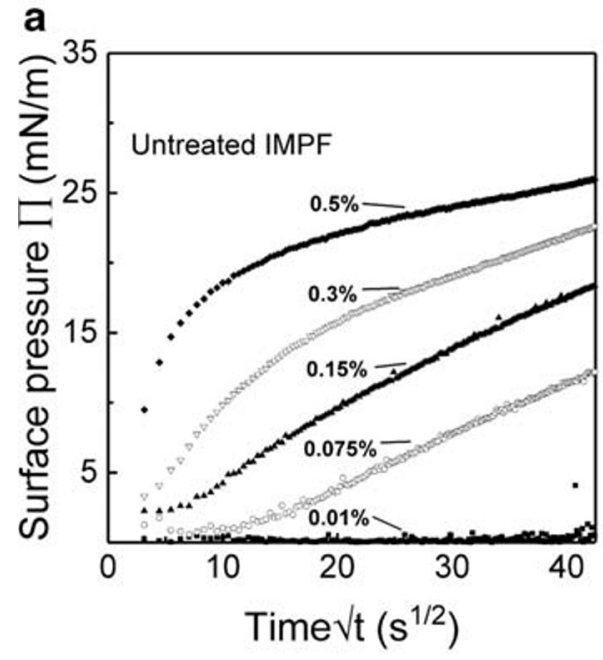

b
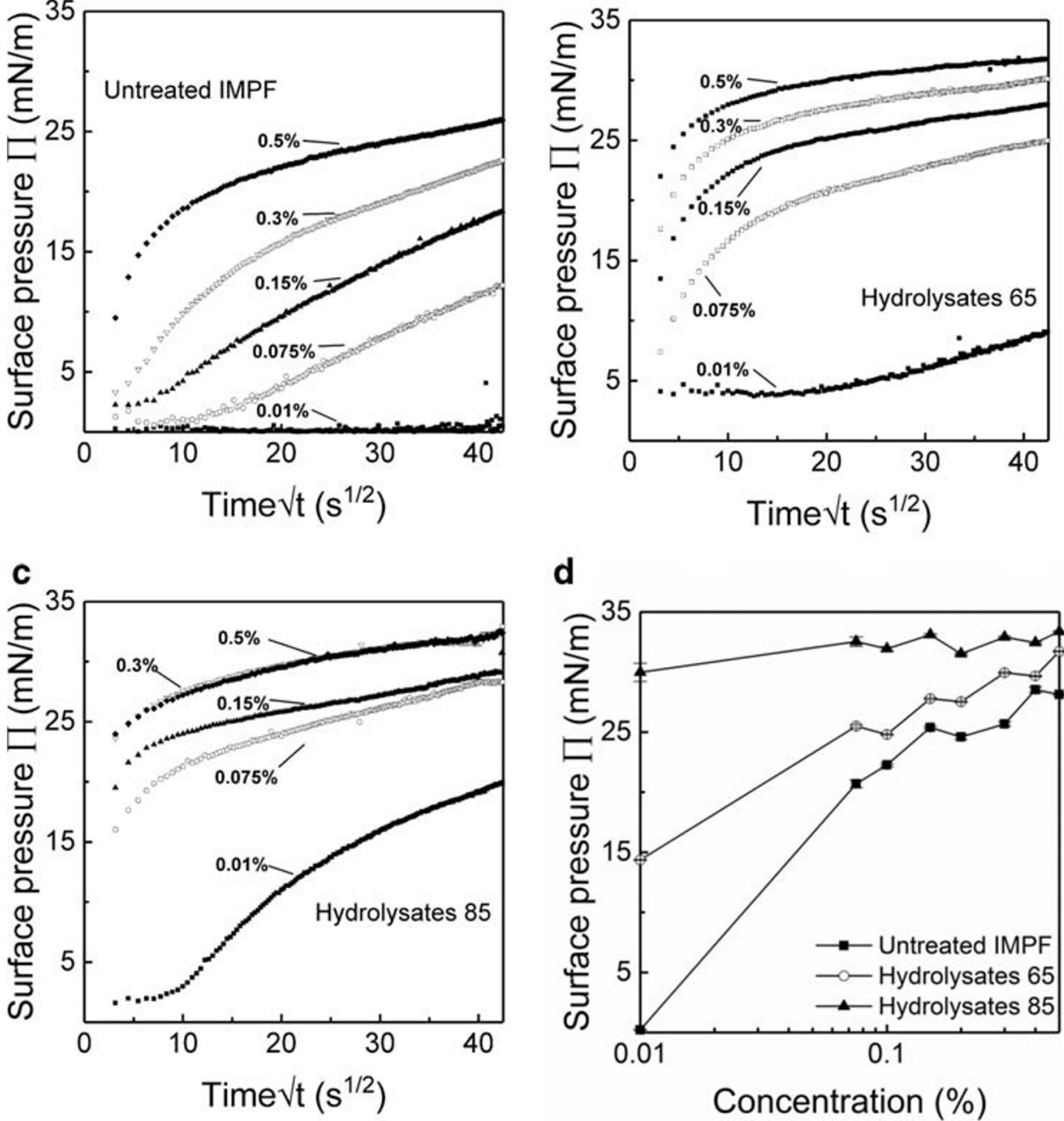

d

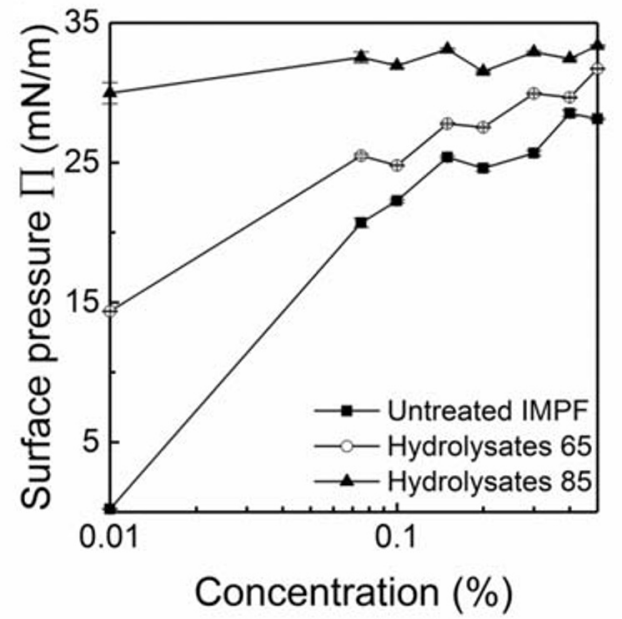

incomplete interfacial coverage due to the presence of mainly large insoluble protein aggregates that are slow to diffuse and adsorb. By comparing the dynamic surface properties of BSA, casein, and buttermilk, Serrien et.al. also reported that proteins with more flexible structures had higher rates of diffusion from the bulk to the surface and thus adsorbed faster at surfaces [35].

\section{Foamability}

A foam is a two-phase system in which gas cells are dispersed in the continuous liquid [14]. In general, the volume of foam formed by the untreated insoluble microalgae protein fraction, Hydrolysates 65 or Hydrolysates 85 increased with the increased protein concentration (Fig. 2). For example, the volume of foams made with untreated insoluble protein fraction significantly increased from $36.43 \pm 1.8 \mathrm{~mL}$ to $174.59 \pm$ $19.5 \mathrm{~mL}$ upon protein concentration increases from $0.1 \%$ to $5 \%(P<0.05)$. In addition, the volume of foam prepared by Hydrolysates 85 was substantially higher than that formed with Hydrolysates 65 followed by the untreated insoluble microalgae protein at the same protein concentration, in particular at lower protein-fraction concentrations $(0.1 \%, 0.5 \%$, and $1 \%$ ) (Fig. 2). These results agrees with those from surface activity and are corroborated by literature whereby foamability of protein depends on the amount and capacity of protein to rapidly adsorb and unfold at the interface [36] (Fig. 1).

The diameter of foam bubbles formed by the differently treated proteins decreased with increasing protein concentration, and hydrolysates-stabilized foams had generally smaller diameters compared to the untreated insoluble microalgae protein fraction (Fig. 3). Since in our setup foaming was done at a constant air pressure, the bubble size decreased due to lower surface tension induced by increased protein concentrations and hydrolysis. The decrease in the diameter of foams formed by different protein fractions can also be observed from the images of the foams. Figure 4 shows microscopic images at four different protein concentrations $(0.1 \%, 0.5 \%, 1 \%$, and $5 \%)$ formed with the untreated fraction and their Hydrolysates. In addition 


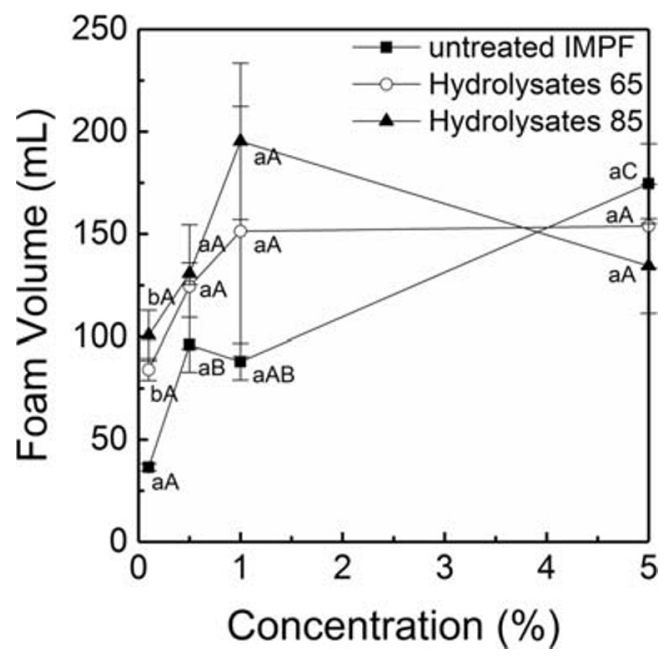

Fig. 2 Volume of foams prepared by the untreated insoluble microalgae protein fraction (untreated IMPF), Hydrolysates 65 and Hydrolysates 85 at extract concentrations of $0.1 \%-5 \%$. Values are mean \pm standard deviation $(n=2)$. The small letters are significance of foams prepared with protein fractions at the same concentration; the capital letter shows significant difference of foams made with the same protein fraction. The $\alpha$-level to present the significant difference is 0.05

to the size changes, there were some structural differences visible in foams stabilized by the examined protein fractions, which is especially visible at the concentration of $0.5 \%$, and $1 \%$ (Fig. 4). The foam bubbles formed by the untreated insoluble microalgae protein had a polygonal appearance, while the Hydrolysates 65- or Hydrolysates 85-formed foams approached spherical (Fig. 4). This may be attributed to differences in bubble size and polydispersity allowing for a more or less close packing of the gas bubbles. The fairly large size of bubbles

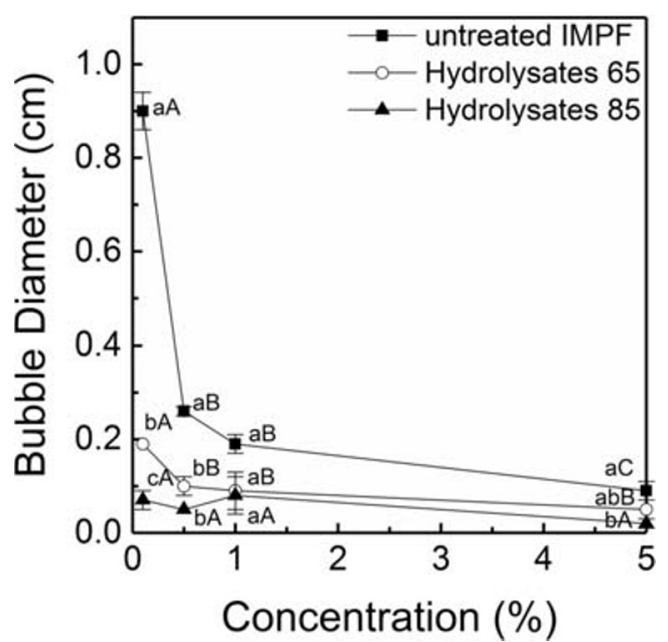

Fig. 3 Bubble diameter of foams prepared by the untreated insoluble microalgae protein fraction (untreated IMPF), Hydrolysates 65 and Hydrolysates 85 at extract concentrations of $0.1 \%-5 \%$. Values are mean \pm standard deviation $(n=2)$. The small letters are significance of foams prepared with protein fractions at the same concentration; the capital letter shows significant difference of foams made with the same protein fraction. The $\alpha$-level to present the significant difference is 0.05 formed with the untreated insoluble microalgea protein fraction leads to bubbles deforming one another [14]. Moreover, the liquid fraction in foams also impact the morphology of bubbles. Dryer foams with liquid fractions of less than 0.05 consisted of polyhedral cells [37]. Increases in liquid fraction allowed for more space to be available between bubbles leading to a wetter foam (e.g. at liquid fractions over 0.15 ) with bubbles having a spherical shape (Table 1) [37].

\section{Foam Stability}

The mechanisms of foam instability include drainage, coalescence, and disproportionation, which eventually leads to bubble collapse, loss of foam structure, texture, and volume [38]. The time within which the foam volume is reduced by half is commonly used to assess the stability of a foam system. In general, the half-life time of foams increased as protein concentrations increased (Table 2). This is because an increasing amount of protein was available to cover interfacial areas [39, 40]. However, there were some substantial differences between the different types of proteins used with respect to stability. First, the most stable foams were those made with Hydrolysates 85 , and stable foams with half-life of 2-3 h could be obtained at a concentration of as little as $0.1 \%$. The foam made with $5 \%$ Hydrolysates 85 did not collapse within the time of observation $(5 \mathrm{~h})$, and was the most stable one manufactured in these studies. Interestingly, foams prepared by Hydrolysates 65 had shorter half-life times compared to those made with the untreated insoluble microalgae protein fraction or Hydrolysates 85 at all concentrations (Table 2).

Contrary to expectations, foams manufactured with the untreated insoluble protein fraction also showed good stabilities that were almost on par with those of Hydrolysates 85 . Fundamentally, the untreated fraction contains mostly dense protein particulates while Hydrolysates 85 contains mostly protein fragments. Hydrolysates 65 contains a mixture of both [19]. This indicates that either a particle-stabilized interface (Pickering effect) or fragment-stabilized interface may stabilize bubbles, while the mixture thereof provides for antagonistic rather than synergistic effects. Particle-stabilized foams can provide stabilization via blocking, i.e. they have shown to structure themselves into layers that are difficult to remove from films $[38,41]$. The apparently antagonistic action of fragments and protein aggregates in Hydrolysates 65 is markedly different from their performance in emulsions, where studies with the same three systems have shown inferior performance of the untreated insoluble microalgae protein fraction to hydrolysates, be it in dilute or concentrated emulsions. In foams, even though the protein aggregates take a longer time to adsorb at interfaces, they appear to generate interfaces that are quite resistant to coalescence and drainage. Hydrolysates 85 contains more soluble protein fragments that are able to unfold and rearrange. They can adsorb more rapidly at the interface, 
Fig. 4 Images of foams made with the untreated insoluble microalgae protein fraction (untreated IMPF), Hydrolysates 65 and Hydrolysates 85 at concentrations of $0.1,0.5,1$ and $5 \%$. The pictures were taken immediately after foaming

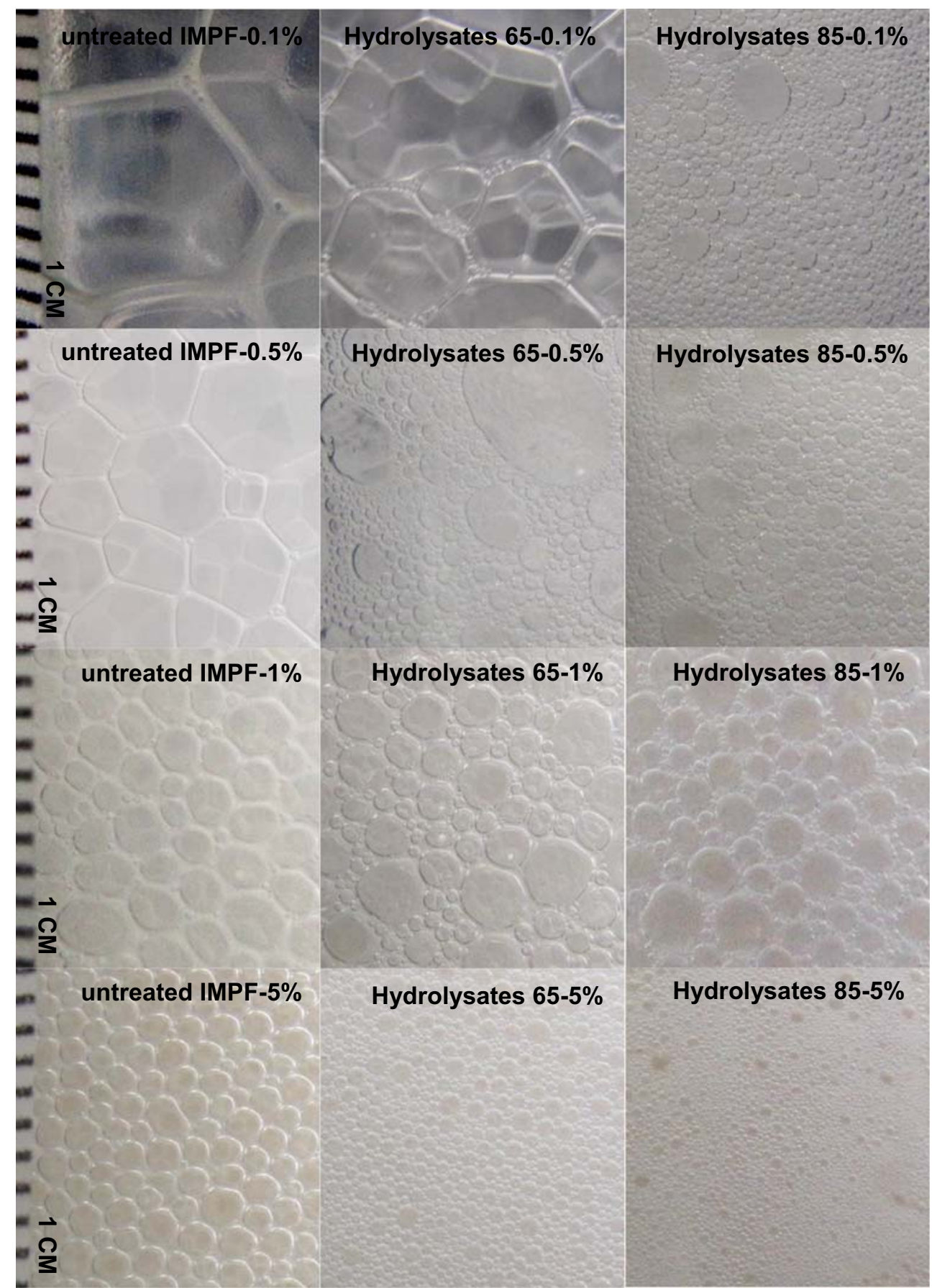

and entangle to form thick, viscous interfacial layers creating stable foams. In contrast, the mixtures of soluble fragments and aggregated dense protein particles appear to not provide good resistance against film rupture. It is likely that the small fragments act therefore as defects in the interface. In those areas, the interface is thin, and their inability to interact or entangle with the larger aggregates may cause the films to rupture due to the flow of liquid around the interfacial film. Such flows may be caused by gravitational effects or surfactant concentration induced effects such as those described by Gibbs-Marangoni $[14,42]$. It should be noted though, that the studies carried out here were done with a sparging foam system. For industrial applications, a whipping or high-speed stirring method is likely to be employed instead. There, much larger shear forces would be exhibited. Future studies should, therefore, be carried out using such methods. This is also because substantial differences in foam stabilizing agent performance have been reported depending on the foam production method used [43]. 
Table 1 The liquid fraction in foams prepared by untreated insoluble microalgae protein fraction (untreated IMPF), Hydrolysates 65 and Hydrolysates 85 at concentrations of $0.1 \%, 0.5 \%, 1 \%$, and $5 \%$

Liquid fraction in foam

Concentration (\%) untreated IMPF Hydrolysates 65 Hydrolysates 85

\begin{tabular}{llll}
\hline 0.1 & 0.03 & 0.03 & 0.09 \\
0.5 & 0.03 & 0.09 & 0.16 \\
1 & 0.08 & 0.15 & 0.20 \\
5 & 0.15 & 0.20 & 0.21 \\
\hline
\end{tabular}

Particle-stabilized foams may perform worse in such studies due to them being less strongly interconnected at the interface compared to protein fragments [22].

\section{Conclusions}

Hydrolysates 65 and Hydrolysates 85 were found to be more surface active than the untreated insoluble microalgae protein fraction having more rapid adsorption rates at low concentrations and higher equilibrium surface pressures. Consequently, Hydrolysates 85 showed the best foamability resulting in the largest foam volume and smallest bubble diameter. In addition, Hydrolysates 85 yielded foams that had the highest stability with long foam half-life times of over $5 \mathrm{~h}$. As such, a thermally induced acid hydrolysis of the insoluble microalgae protein fraction led to the manufacture of a class of technofunctional ingredients that may be of use in the formulation of foam-based foods in the future, such as ice cream, bakery products or dessert. The study also showed some striking differences when comparing performance of the untreated or hydrolyzed proteins in emulsions (dilute or concentrated ones) and in foams: a fact that warrants closer investigation. Finally, some antagonistic effect of mixed particle - fragment interfaces were observed in foams, and studies using various mixing ratios may help to shed some light onto this.

Table 2 Half-life time of foams prepared by the untreated insoluble microalgae protein fraction (untreated IMPF), Hydrolysates 65 and Hydrolysates 85 at extract concentrations of $0.1 \%-5 \%$

Foam half-time

Concentration (\%) untreated IMPF Hydrolysates 65 Hydrolysates 85

\begin{tabular}{llll}
\hline 0.1 & + & + & ++ \\
0.5 & ++ & + & ++ \\
1 & +++ & + & +++ \\
5 & +++ & ++++ & ++++ \\
\hline
\end{tabular}

$(+):<1 \mathrm{~h}(+++): 4-5 \mathrm{~h}$

$(++): 2-3 \mathrm{~h}(++++):>5 \mathrm{~h}$
Acknowledgments We are grateful for the support provided by a fellowship of China Scholarship Council (CSC NO.201506670001) and the Bioeconomy graduate program BBW-ForWerts (200045, BadenWürttemberg, Germany).

Funding Information Open Access funding provided by Projekt DEAL.

\section{Compliance with Ethical Standards}

Conflict of Interest The authors declare that they have no conflict of interest.

Open Access This article is licensed under a Creative Commons Attribution 4.0 International License, which permits use, sharing, adaptation, distribution and reproduction in any medium or format, as long as you give appropriate credit to the original author(s) and the source, provide a link to the Creative Commons licence, and indicate if changes were made. The images or other third party material in this article are included in the article's Creative Commons licence, unless indicated otherwise in a credit line to the material. If material is not included in the article's Creative Commons licence and your intended use is not permitted by statutory regulation or exceeds the permitted use, you will need to obtain permission directly from the copyright holder. To view a copy of this licence, visit http://creativecommons.org/licenses/by/4.0/.

\section{References}

1. L. Grossmann, J. Hinrichs, J. Weiss, Food Res. Int. 116, 283-290 (2019)

2. L. Dai, C.L. Reichert, J. Hinrichs, J. Weiss, Colloids Surf. Physicochem. Eng. Aspects 569, 129-136 (2019)

3. M.H. Bule, I. Ahmed, F. Maqbool, M. Bilal, H.M. Iqbal, Front. Biosci. (Sch. Ed.) 10, 197-216 (2018)

4. M.P. Caporgno, I. Haberkorn, L. Böcker, A. Mathys, Bioresour. Technol. 288, 121476 (2019)

5. E.W. Becker, Biotechnol. Adv. 25(2), 207-210 (2007)

6. B. Klamczynska, W.D. Mooney, in Sustainable Protein Sources, ed. by S. R. Nadathur, J. P. D. Wanasundara, L. Scanlin. (Academic Press, San Diego, 2017), pp. 327-339

7. J.L. García, M. de Vicente, B. Galán, Microb. Biotechnol. 10(5), 1017-1024 (2017)

8. L. Grossmann, S. Ebert, J. Hinrichs and J. Weiss, J. Agric. Food Chem. (2019)

9. S. Ebert, L. Grossmann, J. Hinrichs, J. Weiss, Food Funct. 10(2), 754-764 (2019)

10. E. Suarez Garcia, J. van Leeuwen, C. Safi, L. Sijtsma, M.H.M. Eppink, R.H. Wijffels, C. van den Berg, Bioresour. Technol. 268, 197-203 (2018)

11. A.V. Ursu, A. Marcati, T. Sayd, V. Sante-Lhoutellier, G. Djelveh, P. Michaud, Bioresour. Technol. 157, 134-139 (2014)

12. G.M. Campbell, M.G. Scanlon, D.L. Pyle, Bubbles in Food 2: Novelty, Health and Luxury (AACC International, Inc., St. Paul, 2008)

13. M.S. Sadahira, M.I. Rodrigues, M. Akhtar, B.S. Murray, F.M. Netto, Lwt 89, 350-357 (2018)

14. P. Walstra, in Foams: Physics, chemistry and structure., ed. by A. J. Wilson. (Springer Verlag, New York, 1989), pp. 1-17

15. S. Damodaran, in Advances in food and nutrition research, ed. by J. E. Kinsella, vol 34 (Academic Press, 1990), pp. 1-79

16. E. Dickinson, Food Hydrocoll. 25(8), 1966-1983 (2011) 
17. R. Morales, K.D. Martinez, V.M. Pizones Ruiz-Henestrosa, A.M.R. Pilosof, Ultrason. Sonochem. 26, 48-55 (2015)

18. A. Mohamed, G. Biresaw, J. Xu, M.P. Hojilla-Evangelista, P. Rayas-Duarte, Food Res. Int. 42(1), 107-114 (2009)

19. L. Dai, J. Bergfreund, C.L. Reichert, P. Fischer, J. Weiss, J. Colloid Interface Sci. 551, 297-304 (2019)

20. L. Grossmann, S. Ebert, J. Hinrichs, J. Weiss, Algal Res. 29, 266276 (2018)

21. L. Dai, C.L. Reichert, J. Hinrichs, J. Weiss, J. Sci, Food Agric. 100, 1072-1079 (2020)

22. L. Dai, J. Bergfreund, C.L. Reichert, P. Fischer, J. Weiss, J. Colloid Interface Sci. 551, 297-304 (2019)

23. S.C. Russev, N. Alexandrov, K.G. Marinova, K.D. Danov, N.D. Denkov, L. Lyutov, V. Vulchev, C. Bilke-Krause, Rev. Sci. Instrum. 79(10), 104102 (2008)

24. S.S. Dukhin, G. Kretzschmar, R. Miller, Dynamics of adsorption at liquid interfaces: Theory, experiment, application (Elsevier, 1995)

25. J. Ewert, W. Claaßen, C. Glück, et al., Int. Dairy J. 62, 1-9 (2016)

26. J.E. Kinsella, Food Chem. 7(4), 273-288 (1981)

27. İ. Gülseren, D. Güzey, B.D. Bruce, J. Weiss, Ultrason. Sonochem. 14(2), 173-183 (2007)

28. F.J. Lech, R.J.B.M. Delahaije, M.B.J. Meinders, H. Gruppen, P.A. Wierenga, Food Hydrocoll. 57, 46-54 (2016)

29. P. Wilde, Curr. Opin. Colloid Interface Sci. 5(3), 176-181 (2000)

30. L.M.C. Sagis, E. Scholten, Trends Food Sci. Technol. 37(1), 59-71 (2014)

31. S.E.M. Ortiz, J.R. Wagner, Food Res. Int. 35(6), 511-518 (2002)

32. K.D. Martínez, C. Carrera Sánchez, J.M. Rodríguez Patino, A.M.R. Pilosof, Food Hydrocoll. 23(8), 2149-2157 (2009)
33. J.M. Rodríguez Patino, J. Miñones Conde, H.M. Linares, et al., Food Hydrocoll. 21(5), 782-793 (2007)

34. M.R. Rodríguez Niño, C.C. Sánchez, V.P. Ruíz-Henestrosa, J.M.R. Patino, Food Hydrocoll. 19(3), 417-428 (2005)

35. G. Serrien, G. Geeraerts, L. Ghosh, P. Joos, Colloids and Surfaces 68(4), 219-233 (1992)

36. E. Dickinson, in Foams: Physics, chemistry and structure, ed. by A. J. Wilson. (Springer Verlag, New York, 1989), pp. 39-54

37. W. Drenckhan, S. Hutzler, Adv. Colloid Interf. Sci. 224, 1-16 (2015)

38. B.S. Murray, R. Ettelaie, Curr. Opin. Colloid Interface Sci. 9(5), 314-320 (2004)

39. M. Chen, G. Sala, M.B.J. Meinders, H.J.F. van Valenberg, E. van der Linden, L.M.C. Sagis, Colloids Surf. B. Biointerfaces 149, 5663 (2017)

40. A. Saint-Jalmes, M.L. Peugeot, H. Ferraz, D. Langevin, Colloids Surf. Physicochem. Eng. Aspects 263(1), 219-225 (2005)

41. G.N. Sethumadhavan, A.D. Nikolov, D.T. Wasan, J. Colloid Interface Sci. 240(1), 105-112 (2001)

42. E. Dickinson, Curr. Opin. Colloid Interface Sci. 15(1), 40-49 (2010)

43. L. Grossmann, P. Moll, C. Reichert, J. Weiss, Food Res. Int. 129, $108794(2020)$

Publisher's Note Springer Nature remains neutral with regard to jurisdictional claims in published maps and institutional affiliations. 